\title{
PERANCANGAN SISTEM PAKAR TINGKAT PERSENTASE PENYAKIT ANOREKSIA NERVOSA MENGGUNAKAN METODE DEMPSTER SHAFER
}

\author{
Eva Julia Gunawati Harianja ${ }^{1}$, Junika Napitupulu ${ }^{2}$ \\ ${ }^{1}$ Program Studi Manajemen Informatika Universitas Methodist Indonesia \\ ${ }^{2}$ Program Studi Manajemen Universitas Methodist Indonesia \\ ${ }^{1}$ graziedamanik@gmail.com, 20junica.nptu@gmail.com
}

\begin{abstract}
Anorexia Nervosa (AN) is an eating disorder by making yourself feel hungry (self-starvation). Usually occurs in young women who are stepping on the high school bench (General High School). Their goal is to make themselves hungry so that they have a slim physical appearance and attract the attention of the opposite sex. There are 2 types of Anorexia Nervosa, Restrictive Anorexia Nervosa, people with this type of anorexia greatly limit the amount of food they consume, in fact they often do not eat at all until their bodies become very thin. Anorexia Nervosa Bingepurge, this type of anorexia is almost the same as bulimia. People who suffer from this disorder will eat in large quantities. But after eating, they will tend to feel guilty and then force to vomit back the food they ate. Mahoni Mental Hospital is one of the agencies engaged in health services, as a health agency, it is a must for the agency to improve its services both in terms of speed and timeliness. Mahoni Mental Hospital does not yet have a computerized system or method used to diagnose Anorexia Nervosa. Therefore, there is often a delay in the treatment of anorexia nervosa disorders. This study aims to build an expert system that functions as a tool for the Mahogany Mental Hospital or medical (experts) and medical students in diagnosing Anorexia Nervosa disorders. This study uses the Dempster Shafer method, in diagnosing Anorexia Nervosa disorder, based on the symptoms felt by the patient, then the results of the consultation are how many percent of the patient is affected by Restrictive Anorexia Nervosa or what percentage of the patient is Anorexia Nervosa Bingepurge
\end{abstract}

Keywords: Expert System, Anoreksia Nervosa, Metode Dempster Shafer.

\section{PENDAHULUAN}

Di Indonesia, prevalensi wanita muda yang beresiko untuk menghidapi gangguan makan ialah sebanyak 1222\%. Satu media di Indonesia, pada tahun 2016, melaporkan jumlah remaja dengan gangguan makan semakinmeningkat sebanyak enam kali lipat sejak tahun 2010. Indonesian General Hospital menyatakan sebanyak 140 kasus gangguan makan dilaporkan setiap tahun, tetapi hanya 10 hingga $20 \%$ yang datang berobat (Channel News Asia, 2016).

Penulis dalam melakukan penelitian ini mengambil data di Rumah Sakit Jiwa Mahoni. Rumah Sakit Jiwa Mahoni merupakan rumah sakit jiwa swasta di Medan yang melayani pengobatan penderitaan gangguan Anoreksia Nervosa, dimana gangguan Anoreksia Nervosa banyak terjadi di kalangan masyarakat terutama para remaja yang terobsesi dengan bentuk tubuh hingga melupakan kesehatan tubuh mereka sendiri dan masih banyak masyarakat yang tidak mengetahui bagaimana cara menangani gangguan Anoreksia Nervosa. Sistem pakar merupakan sebuah sistem yang berusaha mengadopsi pengetahuan manusia, dirancang untuk memodelkan kemampuan atau pengetahuan kedalam sebuah sistem untuk menyelesaikan masalah seperti layaknya seorang pakar [1].

Untuk mendiagnosa tingkat persentase Anoreksia Nervosa dengan sistem pakar, maka dibutuhkan sebuah metode yang tepat untuk mendiagnosanya. Oleh karena itu peneliti menerapkan metode Dempster Shafer. Metode Dempster Shafer merupakan suatu representasi, kombinasi dan propagasi ketidakpastian, dimanametode ini memiliki beberapa karakteristik yang secara instuisi sesuai dengan cara berpikir seorang pakar yang memiliki dasar matematika yang kuat [2]. Penelitian ini bertujuan untuk merancang sistem pakar dalam mendiagnosa apakah seseorang itu mengidap penyakit Anoreksia Nervosa dan berapa tingkat persentasse dari penyakit tersebut dengan menggunakan metode Dempster shafer sehingga pasien dan keluarga pasien dapat mudah menangani gangguan Anoreksia Nervosa secara tepat.

\section{LANDASAN TEORI}

\section{Sistem Pakar}

Secara umum, sistem pakar (expert system) adalah sistem yang berusaha mengadopsi pengetahuan manusia ke komputer, agar komputer dapat menyelesaikan masalah seperti yang biasa dilakukan oleh para ahli. Sistem pakar yang baik dirancang agar dapat menyelesaikan suatu permasalahan tertentu dengan meniru kerja daripara ahli. Pakar Pakar adalah seorang individu yang memiliki pengetahuan khusus, pemahaman, pengalaman, dan metode- metode yang digunakan untuk memecahkan persoalan dalam bidang tertentu.

Anoreksia Nervosa Anoreksia Nervosa (AN) adalah gangguan pola makan dengan cara membuat diri merasa tetaplapar (self-starvation). Biasanya terjadi pada remaja wanita yang tengah menginjak bangku SMU (Sekolah Menengah Umum). Adapun tujuan mereka membuat diri lapar adalah agar mereka memiliki penampilan fisik yang ramping dan menarik perhatian lawan jenisnya [3].

Ada 2 tipe jenis Anoreksia Nervosa, yaitu :

1. Anoreksia Nervosa Restriktif, yaitu Anoreksia yang 
penderitanya membatasi jumlah makanan yang mereka konsumsi dan bahkan mereka sering tidak makan sama sekali hingga tubuhnya menjadi sangat kurus.

2. Anoreksia Nervosa Binge-Purge, yaitu Anoreksia yang hampir sama seperti Bulimia. Orang yang menderitagangguan ini akan makan dengan jumlah banyak. Namun setelah makan, mereka akan cenderung merasa bersalah lalu memaksakan untuk memuntahkan kembali makanan yang mereka makan.

Metode Demspster Shafer Metode Dempster Shafer pertama kali diperkenalkan oleh Dempster, yang melakukan percobaan model ketidakpastian dengan range probabilities sebagai probabilitas tunggal. Kemudian pada tahun 1976 Shafer mempublikasikan teori Dempster itu pada sebuah buku yang berjudul Mathematical Theory OfEvidence. Dempster Shafer Theory Of Evidence, menunjukkan suatu cara untuk memberikan bobot kenyakinan sesuai fakta yang dikumpulkan.

Pada teori ini dapat membedakan ketidakpastian dan ketidaktahuan. Teori Dempster Shafer adalah representasi, kombinasi dan propogasi ketidakpastian, dimana teori ini memiliki beberapa karakteristik yang secara instutitif sesuai dengan cara berfikir seorang pakar, namun dasar matematika yang kuat.

Secara umum teori Dempster Shafer ditulis dalam suatu interval: [Belief,Plausibility]. Belief (Bel) adalah ukuran kekuatan evidence dalam mendukung suatu himpunan proposisi. Jika bernilai 0 maka mengindikasikan bahwa tidak ada evidence, dan jika bernilai 1 menunjukkan adanya kepastian. Plausibility (Pls) akan mengurangitingkat kepastian dari evidence. Plausibility bernilai 0 sampai 1 . Jika yakin akan X', maka dapat dikatakan bahwaBel $\left(X^{\prime}\right)=1$, sehingga rumus di atas nilai dari $\mathrm{Pls}(\mathrm{X})=0$. Menurut Giarratano dan Riley fungsi Belief dapat diformulasikan dan ditunjukkan pada persamaan (1):

$$
\operatorname{Bel}(X)=\sum_{Y \subseteq X} m(Y)
$$

Dan Plausibility dinotasikan pada persamaan (2):

$$
\begin{aligned}
& \text { Pls }(X)=1-B e l(X)=1-\sum m(X) \\
& \text { Dimana : } \\
& \text { Bel }(\mathrm{X})=\text { Belief }(\mathrm{X}) \\
& \mathrm{P} 1 \mathrm{~s}(\mathrm{X})=\text { Plausibility }(\mathrm{X}) \\
& \mathrm{m}(\mathrm{X})=\text { mass function dari }(\mathrm{X}) \\
& \mathrm{m}(\mathrm{Y})=\text { mass function } \operatorname{dar}(\mathrm{Y})
\end{aligned}
$$

Teori Dempster Shafer menyatakan adanya frame of discrement yang dinotasikan dengan simbol $(\Theta)$. Frame of discrement merupakan semesta pembicaraan dari sekumpulan hipotesis sehingga sering disebut dengan environment yang ditunjukkan pada persamaan (3):

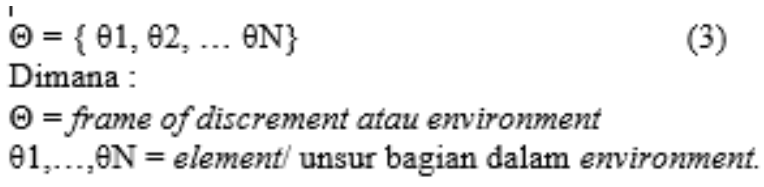

Environment mengandung elemen-elemen yang menggambarkan kemungkinan sebagai jawaban, dan hanya ada satu yang akan sesuai dengan jawaban yang dibutuhkan. Kemungkinan ini dalam teori Dempster Shaferdisebut dengan power set dan dinotasikan dengan $P(\Theta)$, setiap elemen dalam power set ini memiliki nilai intervalantara 0 sampai 1 .

\section{$\mathrm{m}: \mathrm{P}(\Theta)[0,1]$}

Sehingga dapat dirumuskan pada persamaan (4):

$$
\begin{aligned}
& \sum_{X \in \mathrm{P}(\Theta)} m(X)=1 \\
& \text { Dengan } ! \\
& \mathrm{P}(\Theta)=\text { power set } \\
& \mathrm{m}(\mathrm{X})=\text { mass function }(\mathrm{X})
\end{aligned}
$$

Mass function (m) dalam teori Dempster Shafer adalah tingkat kepercayaan dari suatu evidence (gejala), sering disebut dengan evidence measure sehingga dinotasikan dengan (m). Tujuannya adalah mengaitkan ukuran kepercayaan elemen-elemen $\theta$. Tidak semua evidence secara langsung mendukung tiap-tiap elemen. Untuk itu perlu adanya probabilitas fungsi densitas (m). Nilai m tidak hanya mendefinisikan elemen-elemen $\theta$ saja, namun juga semua subsetnya. Sehingga jika $\theta$ berisi $n$ elemen, maka subset $\theta$ adalah $2 \mathrm{n}$. Jumlah semua m dalam subset $\theta$ sama dengan 1. Apabila tidak ada informasi apapun untuk memilih hipotesis, maka nilai :

$\mathrm{m}\{\theta\}=1,0$

Apabila diketahui $\mathrm{X}$ adalah subset dari $\theta$, dengan $\mathrm{m} 1$ sebagai fungsi densitasnya, dan Y juga merupakansubset dari $\theta$ dengan $\mathrm{m} 2$ sebagai fungsi densitasnya, maka dapat dibentuk fungsi kombinasi $\mathrm{m} 1$ dan $\mathrm{m} 2$ sebagai $\mathrm{m} 3$, yaitu ditunjukkan pada persamaan (5):

$$
\begin{aligned}
& m_{3}(Z)=\sum_{X \cap Y=Z} m_{1}(X), m_{2}(Y) \\
& \text { Dimana : }
\end{aligned}
$$

$\mathrm{m}_{3}(\mathrm{Z})=$ mass function dari evidence $(\mathrm{Z})$

$\mathrm{m}_{1}(\mathrm{X})=$ mass function dari evidence $(\mathrm{X})$, yang diperoleh dari nilai keyakinan suatu evidence dikalikan dengannilai disbelief dari evidence tersebut.

$\mathrm{m}_{2}(\mathrm{Y})=$ mass function dari evidence $(\mathrm{Y})$, yang diperoleh dari nilai keyakinan suatu evidence dikalikan dengannilai disbelief dari evidence tersebut [4].

PHP adalah bahasa pemrograman script server-side yang didesain untuk pengembangan web. Selain itu, $P H P$ juga bisa digunakan sebagai bahasa pemrogramanpemrograman umum. PHP disebut bahasa bahasa pemrograman server-side karena $P H P$ diproses pada komputer server. Hal ini berbeda dibandingkan dengan 
bahasa pemrograman client-side seperti JavaScript yang diproses pada web browser (client) [5].

MySQL MySQL adalah sebuah implementasi dari sistemsistem manajemen pada basis data yang relasional yang di distribusikan secara gratis. Setiap pengguna dapat secara bebas menggunakan $M y S Q L$, namun dengan batasan perangkat lunak tersebut tidak boleh dijadikan produk turunan yang bersifat komersialStructured Query Language (SQL) adalah sebuah inti konsep pengoperasian basis data, terutama untuk pemilihan atau seleksi dan pemasukandata-data, yang memungkinkan pada pengoperasian data dikerjakan dengan mudah secara otomatis [5].

Basis Data (Database) Database adalah sekumpulan tabel-tabel yang saling berelasi, relasi tersebut bisa ditunjukkan dengan kunci dari tiap tabel yang ada. Satu database menunjukkan satu kumpulan data yang dipakai dalam satu lingkup perusahaan atau instansi.

Unified Modelling Language Unified Modeling Language (UML) adalah bahasa spesifikasi standar yang dipergunakan untuk mendokumentasikan, menspesifikasikan dan membangun perangkat lunak. UML merupakan metodologi dalam mengembangkan sistem berorientasi objek dan juga merupakan alat untuk mendukung pengembangan sistem.

\section{METODOLOGI}

Alur diagram penelitian yang peneliti gunakan digambarkan dalam bentuk flowchart yang dapat dilihat pada Gambar 1.

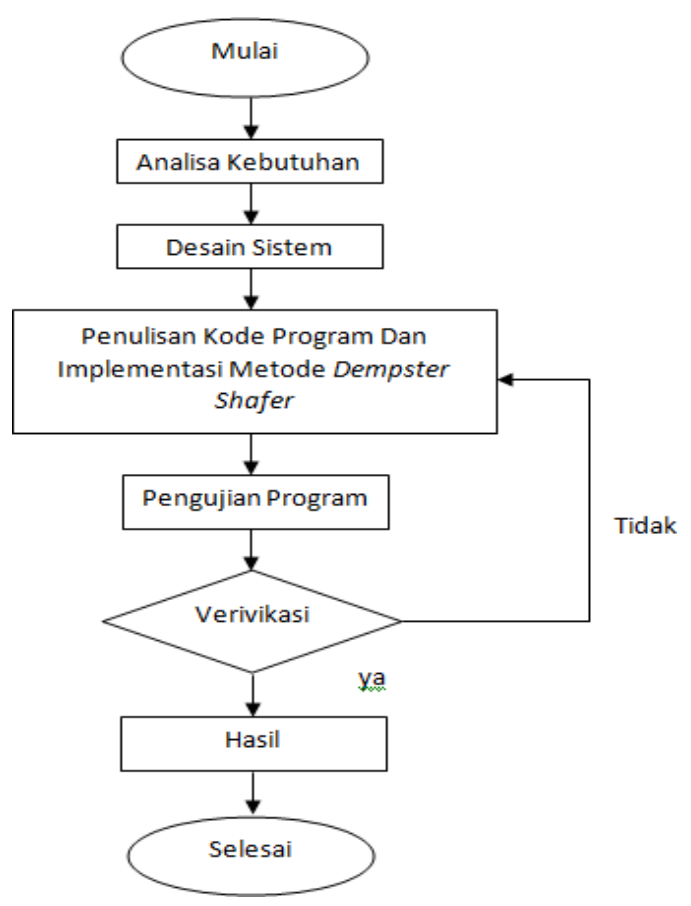

Gambar 1. Flowchart Metode Penelitian

Keterangan :

1. Analisis Kebutuhan
Pada tahap ini dilakukan pengumpulan data-data teori yang terkait dengan data gejala Gangguan Anoreksia Nervosa dan metode Dempster Shafer.

2. Desain Sistem

Peneliti merancang sistem lunak menggunakan pemodelan UML yaitu use case diagram, class diagram, activity diagram dan sequence diagram.

3. Penulisan Kode Program Dan Implementasi Metode Dempster Shafer

Penulisan Kode Program yang peneliti gunakan yaitu menggunakan Pemrograman $P H P$ dan menggunakan database MySQL. Kemudian peneliti menerapkan metode Dempster Shafer ke dalam sistem menggunakan bahasa pemrograman PHP.

4. Pengujian Program

Peneliti melakukan pengujian secara teori maupun praktek. Pengujian teori peneliti menggunakan blackbox testing dan pengujian praktek peneliti menggunakan PHP. Apabila masih terdapat kekurangan sistem maka peneliti memperbaiki kembali sistem.

5. Hasil

Pada tahapan ini, peneliti telah menyelesaikan penelitian dan tujuan penelitian.

Pengumpulan data yang peneliti lakukan menggunakan beberapa cara ataupun teknik. Teknik yang peneliti gunakan yaitu :

1. Observasi/Pengamatan Langsung

Peneliti melakukan observasi/mengamati langsung ke Rumah Sakit Jiwa Mahoni Medan

2. Wawancara (Interview) dengan Ibu Dr. dr. Elmeida Effendy, M.Ked(KJ)., Sp.KJ (K)., selaku Psikiater dengan cara mengajukan pertanyaan langsung kepada beliau.

3. Sampel/Contoh Data

Peneliti mengambil dan mengumpulkan beberapa sampel/contoh data yang dapat digunakan pada penelitianyaitu data-data gangguan Anoreksia Nervosa.

4. Metode Studi Pustaka

Peneliti mengambil referensi terkait berupa jurnal, buku dan karya ilmiah sebagai landasan teori mengenaisistem pakar, gangguan Anoreksia Nervosa dan pemrograman $P H P$.

Analisis Sistem Dengan sistem berkunjung langsung ke Rumah Sakit yang sedang berjalan, terdapat kelemahan dari sistem yang sedang berjalan ini, yaitu :

1. Masyarakat harus datang langsung kerumah sakit untuk berkonsultasi dengan Psikiater.

2. Masyarakat harus antri untuk berkonsultasi dengan Psikiater.

3. Biaya yang dikeluarkan masyarakat dalam berkonsultasi dengan Psikiater terlalu mahal. Sedangkan kelebihan dari sistem yang sedang berjalan ini, yaitu : Kita bisa bertemu langsung dengan psikiater dan bisa menanyakan lebih detail tentang gangguan Anoreksia Nervosa.

Adapun strategi pemecahan masalah yaitu merancang 
sebuah sistem pakar yang baik agar dapat membantu masyarakat dalam mendiagnosa gangguan Anoreksia Nervosa sehingga memudahkan masyarakat dalam mengetahui gejala apa saja dan solusi yang harus di lakukan pasien pengidap gangguan Anoreksia Nervosa.

Perancangan Sistem Sebelum melakukan perancangan pada aplikasi sistem pakar mendiagnosa gangguan Anoreksia Nervosa akan dilakukan pengumpulan data nama-nama gejala beserta jenis dan solusi dari gangguan Anoreksia Nervosa. Pada perancangan ini ada beberapa tahap yaitu, perancangan Use Case Diagram, Class Diagram, Activity Diagram, dan Sequance Diagram. Masukan input pada sistem yaitu gejala-gejala yang dialamipasien, kemudian hasil output pada sistem ini berupa hasil diagnosa nilai densitas dari metode Dempster Shafer dan solusi dari gangguan Anoreksia Nervosa dan perancangan database sistem pakar beserta relasinya.

\section{HASIL PENELITIAN}

Penerapan Metode Dempster Shafer Dalam perancangan sistem pakar ini menggunakan metode Dempster Shafer yaitu dimulai dari sekumpulan fakta-fakta tentang suatu gejala yang diberikan oleh user sebagai masukan ke dalam sistem, kemudian dilakukan perhitungan sampai tujuan akhir berupa diagnosa gangguan Anoreksia Nervosa dan nilai kepercayaannya. Dimana langkahlangkah flowchart menggunakan metode Dempster Shafer dapat dijelaskan sebagai berikut :

1. Saat kita mulai menjalankan sistem, kita berada pada posisi mulai.

2. Sistem akan menampilkan pilihan untuk gejala $\mathrm{i}(\mathrm{g} 1)$ $\left\{m_{1}(X)\right\}$.

3. Kemudian menghitung gejala $\mathrm{i}(\mathrm{g} 1) \quad\left\{\mathrm{m}_{1}(\mathrm{X})\right\}$ menggunakan rumus Dempster Shafer.

4. Banyak gejala $=1$.

5. Jika jawaban "ya", maka hasilnya penyakit tidak diketahui. Proses selesai.

6. Jika jawaban "tidak", pada gejala i(g1), maka sistem akan menampilkan pilihan untuk gejala $\mathrm{i}+1(\mathrm{~g} 2)$.

7. Kemudian menghitung $\mathrm{i}+1(\mathrm{~g} 2)\left\{\mathrm{m}_{2}(\mathrm{Y})\right\}$.

8. Kemudian dikombinasikan dengan menghitung gejala $1(\mathrm{~g} 1)\left\{\mathrm{m}_{1}(\mathrm{X})\right\}$ dan gejala $2(\mathrm{~g} 2)\left\{\mathrm{m}_{2}(\mathrm{Y})\right\}$.

9. Kemudian gejala habis.

10. Jika jawaban "tidak", maka sistem akan menampilkan kembali pilihan sampai gejala selesai dijawab danditayangkan berulang pada posisi ini.

11. Jika jawaban "ya", maka sistem akan mengetahui kesimpulan penyakit yaitu penyakit dengan nilai densitasnya. Proses selesai.

Berikut adalah Flowchart dari tahapan-tahapan rumus metode Dempster Shafer :

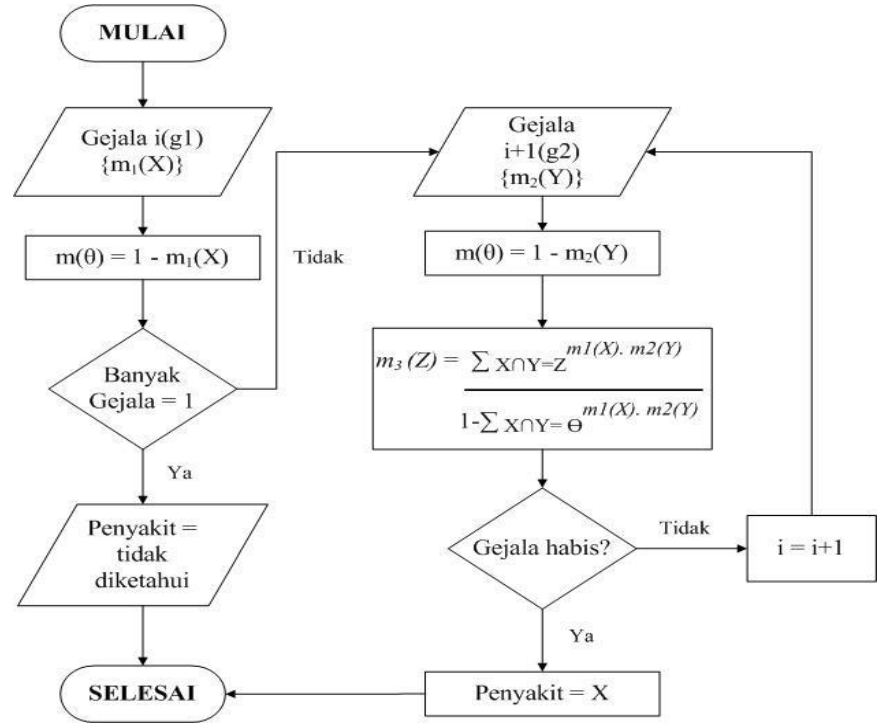

Gambar 2. Flowchart Metode Dempster Shafer

Berikut ini data gangguan yang dirancang pada Tabel 1 dibawah ini :

Tabel 1. Data Gangguan

\begin{tabular}{cl}
\hline Kode Gangguan & \multicolumn{1}{c}{ Nama Gangguan } \\
\hline GG01 & Anoreksia Nervosa Restriktif \\
\hline GG02 & Anoreksia Nervosa Binge-Purge \\
\hline
\end{tabular}

Berikut ini data gejala yang dirancang pada Tabel 2 dibawah ini :

\begin{tabular}{clc}
\multicolumn{2}{c}{ Tabel 2. Data Gejala } \\
\hline $\begin{array}{c}\text { Node Gejala } \\
\text { GJ01 }\end{array}$ & \multicolumn{1}{c}{ Nerat Badan Menurun Drastis } & Nilai Densitas \\
\hline GJ02 & Merasa Rendah Diri & 0,6 \\
\hline GJ03 & Berolahraga Secara Berlebihan Setelah Makan & 0,9 \\
\hline GJ04 & Kehilangan Gairah Seksual & 0,8 \\
\hline GJ05 & Tekanan Darah Rendah & 0,8 \\
\hline GJ06 & Rambut, Kuku, Gigi Mudah Rusak & 0,9 \\
\hline GJ07 & Menghindari Makan Didapan Orang Lain & 0,6 \\
\hline GJ08 & Menggolong-golongkan Makanan Yang Baik Dan & 0,5 \\
\hline GJ09 & Yang Jelek Bagi Tubuhnya & 0,6 \\
\hline GJ10 & Bergegas Kekamar Mandi Setelah Makan & 0,9 \\
\hline GJ11 & Takut Berat Badan Naik & 0,6 \\
\hline
\end{tabular}

Dari tabel diatas, sistem dapat memberikan informasi mengenai ganngguan Anoreksia Nervosa, jika gejala pada pasien sesuai dengan yang di input, maka aturan (rule) yang dapat digunakan untuk mendiagnosa gangguan Anoreksia Nervosa dapat dilihat pada Tabel 3. sebagai berikut ini :

Tabel 3. Aturan (Rule)

\begin{tabular}{llc}
\hline No & \multicolumn{1}{c}{ Aturan (Rule) } & Kode Aturan \\
\hline $\mathbf{1}$ & $\begin{array}{l}\text { IF GJ01 AND GJ02 AND GJ04 AND GJ05 AND GJ06 AND GJ07 } \\
\text { AND GJ08 AND GJ10 THEN GG01 }\end{array}$ & R1 \\
\hline $\mathbf{2}$ & $\begin{array}{l}\text { IF GJ01 AND GJ03 AND GJ06 AND GJ07 AND GJ08 AND GJ09 } \\
\text { AND GJ10 AND GJ11 THEN GG02 }\end{array}$ & R2 \\
\hline
\end{tabular}

Tabel keputusan digunakan sebagai acuan dalam membuat pohon keputusan dan kaidah yang digunakan. Berdasarkan data yang ada, maka tabel keputusan pada sistem pakar mendiagnosa gangguan Anoreksia Nervosa dapat dilihat pada Tabel 4 sebagai berikut ini : 
Tabel 4. Tabel Keputusan

\begin{tabular}{|c|c|c|c|c|c|c|c|c|c|c|c|}
\hline \multirow{2}{*}{$\begin{array}{c}\text { Kode } \\
\text { Gangguan } \\
\text { (GG) }\end{array}$} & \multicolumn{11}{|c|}{ Kode Gejala(GJ) } \\
\hline & $\stackrel{\Omega}{0}$ & 总 & 己气 & 20: & 密 & 气ุ & ટ્ટુ & શ્ટે & : & $\stackrel{2}{0}$ & $\stackrel{\Omega}{3}$ \\
\hline GG01 & $\checkmark$ & $\sqrt{ }$ & & $\sqrt{ }$ & $\sqrt{ }$ & $\sqrt{ }$ & $\sqrt{ }$ & $\checkmark$ & & $\sqrt{ }$ & \\
\hline GG02 & j & & $\sqrt{ }$ & & & $\sqrt{ }$ & $\sqrt{ }$ & $\sqrt{ }$ & $\sqrt{ }$ & j & $\sqrt{ }$ \\
\hline
\end{tabular}

Mencari Perhitungan Gangguan Anoreksia Nervosa Berikut langkah-langkah perhitungan metode Dempster shafer untuk mencari gangguan Anoreksia Nervosa : Untuk mengetahui hasil konsultasi penyebab gangguan ini, dilakukan pengujian proses konsultasi. Proses pengujian sistem berupa masukan data gejala yang dialami oleh pasien antara lain :

Gejala 1 : Berat Badan Menurun Drastis (GG01,GG02) $\mathrm{m}_{1}(\mathrm{GG} 01, \mathrm{GG} 02)=0.6$

$$
\begin{aligned}
\mathrm{m}_{1}(\varnothing) & =1-\mathrm{m}_{1}(\mathrm{GG} 01, \mathrm{GG} 02) \\
& =1-0.6=0.4
\end{aligned}
$$

Gejala 2 : Merasa Rendah Diri (GG01)

$$
\begin{array}{ll}
\mathrm{m}_{2}(\mathrm{GG} 01) & =0.9 \\
\mathrm{~m}_{2}(\varnothing) & =1-\mathrm{m}_{2}(\mathrm{GG} 01) \\
& =1-0.9=0.1
\end{array}
$$

\begin{tabular}{llllll}
\hline & & GG01 & 0,9 & $\emptyset$ & 0,1 \\
\hline GG01,GG02 & 0,6 & GG01 & 0,54 & GG01,GG02 & 0,06 \\
\hline$\varnothing$ & 0,4 & GG01 & 0,36 & $\emptyset$ & 0,04
\end{tabular}

Sehingga dapat dihitung $\mathrm{m}_{3}$ yaitu :

$$
\begin{aligned}
\mathrm{m}_{3}(\mathrm{GG} 01) & =0,54+0,36=0,9 \\
& (1-0) \quad 1 \\
\mathrm{~m}_{3}(\varnothing) & =0,04 \\
= & 0,06 \\
= & 0,04
\end{aligned}
$$

\begin{tabular}{|c|c|c|c|c|c|}
\hline \multirow[t]{2}{*}{$\mathrm{m}_{5}(\varnothing)$} & \multicolumn{5}{|c|}{$\begin{array}{l}=1-\mathrm{m}_{5}(\mathrm{GG} 01, \mathrm{GG} 02) \\
=1-0.6=0.4\end{array}$} \\
\hline & & GG01,GG02 & 0,6 & $\emptyset$ & 0,4 \\
\hline GG01 & 0,9 & GG01 & 0,54 & $\mathrm{GG} 01$ & 0,36 \\
\hline $\mathrm{GG} 01, \mathrm{GG} 02$ & 0,08 & $\mathrm{GG} 01, \mathrm{GG} 02$ & 0,048 & $\mathrm{GG} 01, \mathrm{GG} 02$ & 0,032 \\
\hline$\emptyset$ & 0,02 & $\mathrm{GG} 01, \mathrm{GG} 02$ & 0,012 & $\emptyset$ & 0,008 \\
\hline
\end{tabular}

Gejala 7 : Menghindari Makan Didepan Orang Lain

$$
\begin{aligned}
& \mathrm{m} 3(\mathrm{GG} 01, \mathrm{GG} 02)=0,06 \\
& (\mathrm{GG} 01, \mathrm{GG} 02) \mathrm{m} 4 \\
& (\mathrm{GG} 01, \mathrm{GG} 02)=0.5 \\
& \mathrm{~m} 4(\varnothing)=1-\mathrm{m} 4(\mathrm{GG} 01, \mathrm{GG} 02) \\
& =1-0.5=0.5
\end{aligned}
$$

\begin{tabular}{llllll} 
& & GG01,GG02 & 0,5 & $\emptyset$ & 0,5 \\
\hline GG01 & 0,9 & GG01 & 0,45 & GG01 & 0,45 \\
\hline GG01,GG02 & 0,06 & GG01,GG02 & 0,03 & GG01,GG02 & 0,03 \\
\hline$\emptyset$ & 0,04 & GG01,GG02 & 0,02 & $\emptyset$ & 0,02
\end{tabular}

Sehingga dapat dihitung $\mathrm{m}_{4}$ yaitu :

$$
\begin{aligned}
& \mathrm{m}_{4}(\mathrm{GG} 01) \quad=\frac{0,45+0,45}{(1-0)}=\frac{0,9}{1}=0,9 \\
& \mathrm{~m}_{4}(\mathrm{GG} 01, \mathrm{GG} 02)=\frac{0,03+0,02+0,03}{(1-0)}=\frac{0,08}{1}=0,08 \\
& =0,02=0,02 \\
& \mathrm{~m}_{4}(\varnothing)=0,02
\end{aligned}
$$

Gejala 10 : Takut Berat Badan Naik (GG01,GG02)m 5 $(\mathrm{GG} 01, \mathrm{GG} 02)=0.6$
Sehingga dapat dihitung $\mathrm{m}_{5}$ yaitu :

$$
\begin{aligned}
\mathrm{m} 5(\mathrm{GG} 01) & =\frac{0,54+0,36}{(1-0) 1}=\frac{0,9}{1}=0,9 \\
\mathrm{~m} 5(\mathrm{GG} 01, \mathrm{GG} 02) & =\frac{0,048+0,012+0,032}{}=\underline{0,092} \\
& =0,092 \\
\mathrm{~m} 5(\varnothing) & =\frac{0,008}{(1-0)}=\frac{0,008}{1}=0,008
\end{aligned}
$$

Maka didapat nilai kepastian kombinasi Metode Dempster Shafer bahwa pasien menderita gangguan Anoreksia Nervosa Restriktif dengan densitas dari keempat gejala tersebut adalah $0,9 * 100 \%=90 \%$ Dengan nilai densitas $90 \%$ maka pasien memiliki evidence yang cukup kuat mengalami gangguan Anoreksia Nervosa Restriktif.

Hasil Gambar 3 merupakan tampilan halaman konsultasi, user dapat melakukan konsultasi Anoreksia Nervosa

dengan cara mengisi nama pasien serta usia pasien, dan setelah itu tekan tombol mulai untuk memulai konsultasi.

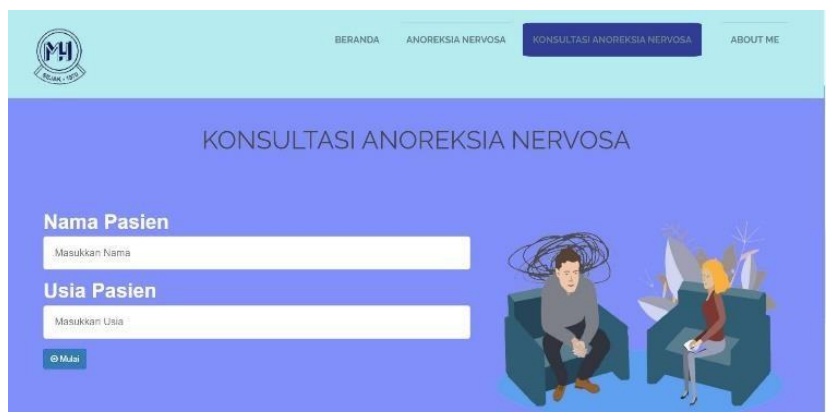

Gambar 3. Tampilan Halaman Konsultasi

Gambar 4 merupakan tampilan halaman tanya jawab. User akan diberikan beberapa pertanyaan mengenai kondisi tubuh user, dan user dapat menjawabnya dengan memilih "Ya" atau "Tidak", setelah itu user dapat menekan tombol selanjutnya untuk masuk ke pertanyaan selanjutnya.

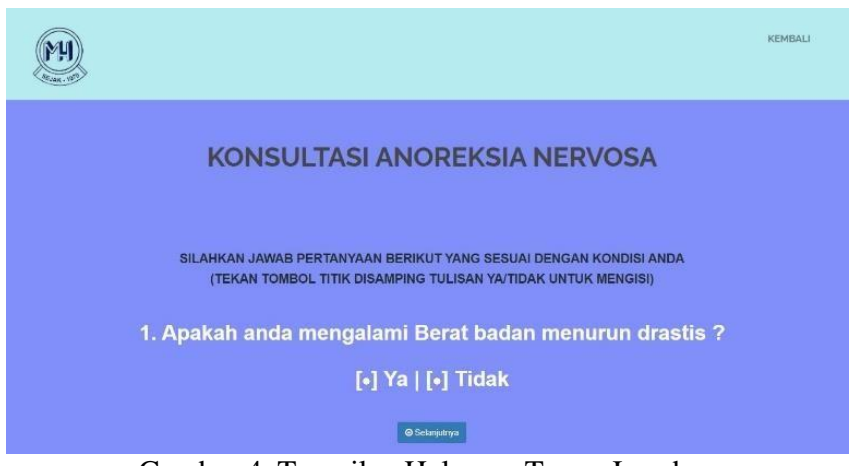

Gambar 4. Tampilan Halaman Tanya Jawab

Gambar 5 merupakan tampilan halaman hasil konsultasi dari proses tanya jawab yang dilakukan oleh user sebelumnya. Pada tampilan ini, user dapat melihat jumlah pertanyaan yang dijawab "Ya" oleh user, dan user dapat menekan tombol diagnosa untuk melihat 
hasil diagnosa user. Hasil diagnosa akan menampilkan persentase dari user mengidap gangguan Anoreksia
Nervosa dan juga saran bagi user.

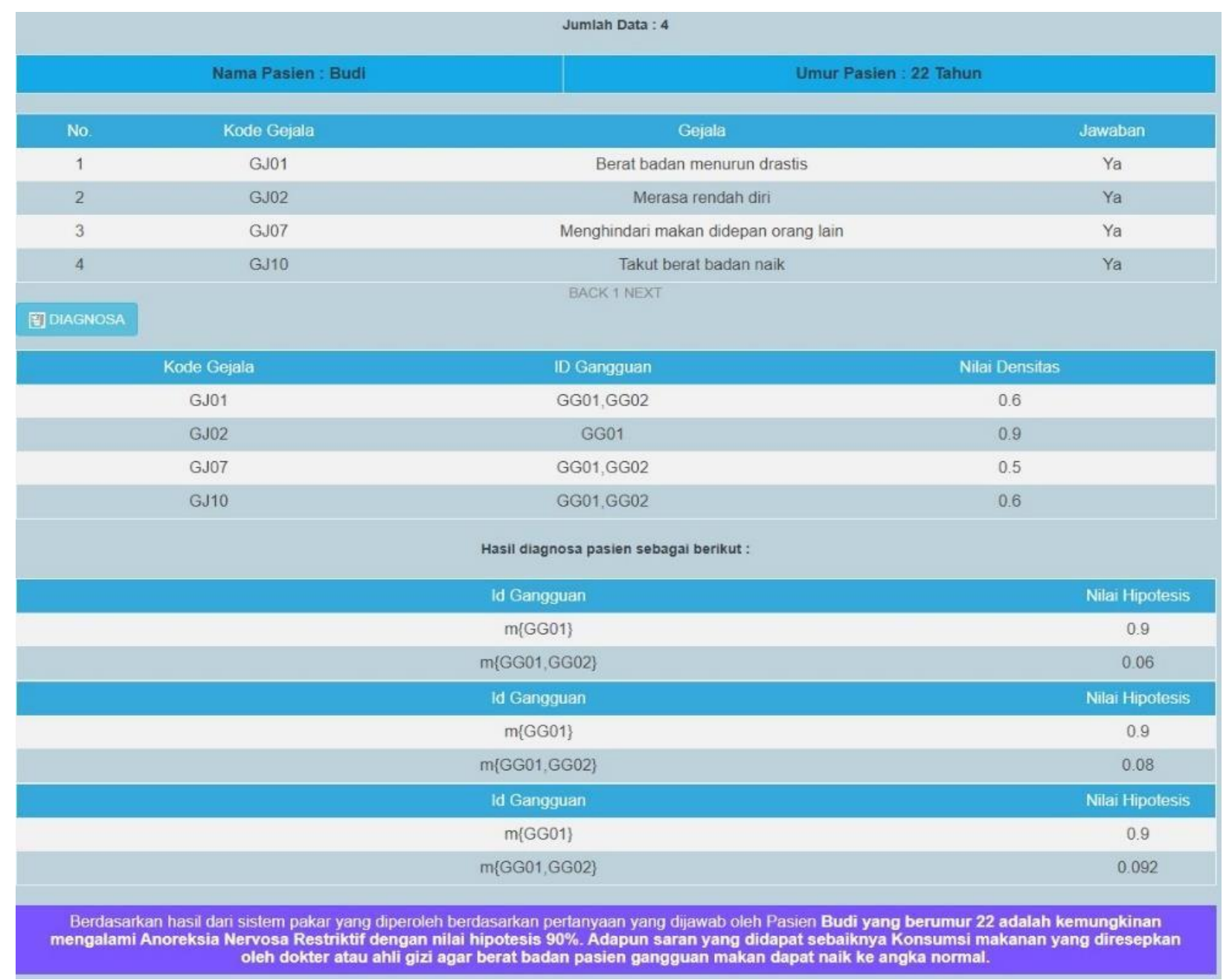

Gambar 5. Tampilan Halaman Hasil Konsultasi

\section{KESIMPULAN}

Beberapa kesimpulan yang dapat diambil melalui pembahasan-pembahasan pada bab-bab sebelumnya dalam hal pembuatan aplikasi yang dilakukan oleh peneliti adalah sebagai berikut :

1. Sistem pakar yang di bangun dapat memberikan informasi mengenai gangguan Anoreksia Nervosa kepadamasyarakat.

2. Sistem pakar yang dirancang akan memberikan hasil konsultasi berupa persentase jenis gangguan diderita serta solusi terhadap gangguan yang dialami penderita.

3. Sistem yang di bangun mempermudah pengguna untuk mengetahui gangguan Anoreksia Nervosa Restriktif

atau Anoreksia Nervosa Binge-Purge yang sedang diderita.

\section{DAFTAR PUSTAKA}

[1] Eridani, D., Rifki, M. A., \& Isnanto, R. R. (2018). Sistem Pakar Pendiagnosis Gangguan Kecemasan Menggunakan Metode Forward
Chaining Berbasis Android. Edu Komputika Journal.

[2] Sitio, A. S. (2018). Sistem Pakar untuk Mendiagnosa Penyakit Jantung Menggunakan Metode Dempster Shafer. Journal of Informatic Pelita Nusantara.

[3] Krisnani, H., Santoso, M. B., \& Putri, D. (2017). Gangguan Makan Anorexia Nervosa dan Bulimia Nervosa pada Remaja. Prosiding Penelitian dan Pengabdian kepada Masyarakat.

[4] Sinaga, M. D., \& Sembiring, N. B. (2016). Penerapan Metode Dempster Shafer untuk Mendiagnosa Penyakit dari Akibat Bakteri Salmonella. Cogito Smart Journal.

[5] Agusvianto, H. (2017). Sistem Informasi Inventori Gudang untuk Mengontrol Persediaan Barang pada Gudang Studi Kasus : PT.Alaisys Sidoarjo. JIEET (Journal Information Engineering and Educational Technology). 